\title{
El burdel revolucionario
}

Maité Loría López.

\section{Burdel Las Tres Rosas}

Tegucigalpa, Honduras

1978

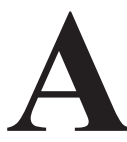
bro mis ojos a las once de la mañana con esa sensación de tener un cenicero en la garganta. La luz entra intrépidamente por la rendija de esta ventana vieja que en algún momento era el centro de mis cumplidos. Al mirar el humo y el polvo que flotaba sigilosamente por la habitación, cargando mis penas, mis memorias y mis alegrías, recordé con una fugaz melancolía el día en que Don Reneé me dijo que me iba a mandar unas ventanas francesas, porque "una joya como usted no podía estar asomándose por la ventana con glamour si lo que parece es una sirvienta de hacienda".

Pedro, el hijo de doña Marielos, me las vino a instalar. Recuerdo que su mamá esperó afuera con el ceño fruncido sosteniendo una canasta de tortillas calientes y dando nerviosos golpecitos con su pie, como si poner una ventana se hiciera en cuestión de segundos. El pobre muchacho había entrado con la mirada cabizbaja, sujetando con tanta fuerza su caja de madera descolorida, donde traía sus herramientas oxidadas, que las manos se le veían pálidas casi color lila, el crucifijo guindando de su cuello al aire libre se tambaleaba de lado a lado, seguramente un intento de su madre de proteger a su chamaco de nuestras tentaciones, nosotras las mujeres de carnes pecadoras. ¿Sabría ella que a más de uno le encanta rezar salmos mientras explota contra nuestras carnes? Bastó con que Julieta se asomara por la puerta de la cocina para que el muchacho dejara caer la caja y quedara estupefacto ante sus rebosantes senos en el babydoll de encajes color burdeo que mandé a traer de Italia. Con un grito de doña Marielos, que se asomaba nerviosa por la puerta principal, Pedro recogió con rapidez las herramientas y subió al tercer piso, siguiéndome el paso, y respirando como si los demonios le estuviéramos acechando en cada esquina. Al abrir las puertas de mi recámara, le señalé las ventanas, y me senté sobre la cama hecha y perfumada a fumarme un cigarro mientras administraba el trabajo del muchacho. Fue ahí cuando le vi el miembro marcado en los jeans desteñidos y noté cómo sus cachetes estaban ruborizados. Doña Marielos le gritó desde la acera: "¡apúrate que tenemos mucho trabajo que hacer hoy! Ay de ti que te me desaparezcas porque te dejo la plancha marcada en la espalda, ¡¿me escuchás?!" Pedro balbuceó una respuesta y de tanta pena de verlo ahí con el miembro endurecido, las herramientas, $\mathrm{y}$ la mamá gritando, me fui a traerle un vasito con agua ardiente para que se le bajara la conmoción y terminara la tarea. Cuando volví, Pedro le había pegado semejante 
martillazo a la ventana que quedó con un hueco irreparable en el lado izquierdo, y estaba nerviosamente tratando de ocultar el error. Le entregué el vaso escondiéndome detrás de la ventana, no me fuera a ver su mamá, y le dije: "no te preocupes muchachito, tómate esto y concéntrate bien, que si me haces otro hueco te tiro por la ventana misma". El aguardiente le cayó como alma al cielo, y rapidito el muchacho me agradeció con la mirada e instaló las ventanas sin más daños. A pesar de todo, el hueco me había servido para sostener innumerables palitos de incienso por más de veinte años. Pedro eventualmente se convirtió en cliente regular, enamorado empedernido de Julieta, aun cuando se le empezaron a caer las tetas y a pesar de sus malos humores.

Los gritos en la calle me desprenden de mis memorias, me siento sobre la cama buscando con mis pies las pantuflas de pluma de cisne que me regalaron las chicas el año pasado para celebrar el aniversario de Las Tres Rosas. Me tiro la bata en la espalda mientras busco mis cigarros con una mano y con la otra me acomodo el sostén. Estos malditos alambres se me incrustan en el esternón como si quisieran sacarme el corazón de una vez por todas. ¿Será que todas nos tenemos que levantar con esa sensación de sofoque? Abro la vieja ventana, y veo a un grupo de vecinos en la esquina reunidos alrededor de un televisor portátil, "!la revolución, la revolución sandinista ha llegado al poder, Nicaragua se libera!” "¡Cállense hombres que nos van a tirar al ejército encima! Vengan, voy a poner café con yuscarán," les grito por la ventana.
Bajo a poner la tetera sobre el fogón mientras los vecinos se acomodan en las sillas, casi todos han sido nuestros clientes y las cuantas mujeres que están acá son compañeras de trabajo o son socias; nos planchan y lavan las delicadas ropas del oficio, nos arreglan las zapatillas, nos venden tortillas y nosotras les vendemos cremas, aceites, ungüentos, les leemos las cartas y les hacemos limpias. El oficio del cuerpo, el placer, el amor y el pueblo son inseparables. Aquí hacemos de todo, ¿cómo más vamos a sobrevivir esta sucia guerra y este mierdero de hombres asesinos y mujeres de clase alta que nos quitan la mirada? Don Pedro, ya grande, ya merecedor del Don, pone la televisión portátil en el centro de la mesa, le arregla las antenas y le da unos golpecitos hasta que la pantalla muestra más imagen que líneas grisáceas de estática. Es ahí cuando lo veo, El Danto, ni más ni menos, un revolucionario líder de nuestras tierras. En la tele dicen que se llama Germán Pomares y es fundador del Frente Sandinista de la Liberación Nacional.

No fue hace mucho que ese hombre había aparecido por acá, pidiendo un cuarto y rechazando la oferta de acompañantes. Las colegas estábamos curiosas por saber sobre el caballero de mirada seria y ojos brillantes. Estaba claro que el hombre se andaba escurriendo de la ley, y pues claro, esta casa es el lugar donde los escurridos venimos a parar. Recuerdo que entró con un maletín mal cosido y sucio, sin bajar la mirada pero sin alimentarse de los manjares a su alrededor, subió al segundo piso donde Magdalena le mostró su cuarto, el lavabo y le preguntó si habría algo que podría hacer por él. Él pidió que le trajera un teléfono al cuarto y que si de casualidad 
le podíamos colaborar con unos cigarrillos en nombre de la revolución. Cuando bajó Magdalena, tenía esa expresión de muchacha ilusa, y me dijo: "ese es el tipo de hombre que nos manda San Antonio Guatemalteco," y venía cargando el Santo con una velita para prenderla en el altar de la cocina. Se perfumó el cuerpo y arregló una bandeja con el teléfono, los cigarros, que había sacado de su propio botín, y un tazón con una granadilla y una maracuyá, los manjares mojados de la excitación. Le encomendó al Santo que la guiara y la vi desaparecer por las escaleras mientras yo me preparaba para la tanda de la noche; celebraríamos la estadía de un sandinista. No habían pasado dos minutos cuando Magdalena bajó con la cara roja y lágrimas en los ojos, "Ay Rosa," suspiró. El hombre había agarrado el teléfono y los cigarros, y prácticamente le había cerrado la puerta en la cara. De verla ahí, tan niña, tan soñadora, me ha causado un dolor en el alma que no quedó otra que prenderle un par de velas más al santo, a ver si se quemaba el cabrón, y convidarle mis cigarros a la niña que había entregado los suyos pensando en el amor. Todavía tierna en sus años, Magdalena no sabía que la vida en estas tierras era un saldo de injusticias y carencias. No sabía que llegaría una a la vejez soñando con hombres que regalan ventanas francesas y agradeciendo los huecos que te hicieron, porque te ganaste a un cliente y un espacio pa' quemar tus inciensos, pa' limpiar el alma y pa' soñar con la revolución.

Esta mañana, viendo al hombre misterioso que le rompió el corazón a Magdalena, y me costó un paquete de cigarros, recordé que en el 77 un tal guerrillero Gaspar había publicado una carta que había llegado hasta la cocina de esta casa, incitando a los sandinistas a luchar "como soldados del señor y como soldados del FSLN;" declaraba que "había visto las heridas de su pueblo, había tocado con sus manos la vileza, el escarnio, el engaño, el latronicio de la familia Somoza; había escuchado el gemido del pueblo en la noche de la cerrada de las bayonetas; y pedía a los hermanos nicas que por su amor a Cristo apoyaran la lucha del Frente Sandinista, para que el día de la revolución del pueblo no se siguiera atrasando". Busco en las gavetas de la cocina hasta encontrar la vieja noticia, pensando que nosotras también habíamos apoyado, no por ningún señor ni por nada grande más que por el hecho de ser también nosotras luchadoras en un mundo que por un lado nos niega el pan y por el otro nos culpa de pecadoras, tentadoras y enfermas sociales. Acá, en esta casa, se han refugiado muchas mujeres, hombres tristes y hombres hambrientos, se han hecho reuniones con gentes que decían estar también haciendo la revolución hondureña, un día llegó una señora costarricense que nos contaba que ellas eran más que putas, ellas eran mensajeras de los hombres bananeros y la lucha de los trabajadores, y ahora mire usted, acá también llegó uno de los fundadores del Movimiento Sandinista. Acá llegamos todos a parar y somos el lugar que siempre abre las puertas pero que nadie menciona, porque ahí sí, Dios guarde sepan que estaban la putas involucradas, no vayamos a manchar la revolución y la libertad con nuestros perfumes de rosas y nuestros labios carmesí. 


\section{Las Putas también amamos a la Unión Soviética}

Tapachula, México

1963

En el año 1930, ya yo había salido de La Puebla para buscar negocio en el centro de San José, donde los hombres del mercado central se habían convertido en mis clientes. Un viernes de semana santa, mientras me limaba las uñas en la esquina del mercado, pasó Juan Morales en su carreta y me dijo: "macha, ¿ya está aceptando clientes o estoy interrumpiendo en su tiempo personal?" Me causó gracia que el hombre pensara que estar parada en una esquina era tiempo personal, pero tomé el comentario con cariño porque su tono era respetuoso y estaba más concentrado en la lima de uñas que en el escote al descubierto. Me monté en su carreta y le aseguré que no pretendía salir de San José, ya se habían escuchado historias de hombres que se llevaban mujeres montaña arriba y allá aparecían tres o cuatro degenerados que la dejaban a una sin poder caminar por una semana. Juan Morales me miró a los ojos y me prometió que sus intenciones eran invitarme a un café y que si le gustaba su compañía él me pagaría la acostada. Nos tomamos un café en la estación del Atlántico, mientras le llenaban la carreta de bananos, también ordenó galletas de panadería y una manita de pan con natilla. Me contó que trabajaba en las bananeras y que estaba en San José cargando producto para que los capataces del Pacífico vieran la calidad de las plantaciones de Bananito Sur.

Al caer la tarde, me preguntó con ojos esperanzados si me había gustado el café y su compañía, de así serlo, había una casa cerca donde podíamos dejarnos tocar, y por supuesto me pagaría por adelantado. Fue tan lindo que casi me acuesto con él gratis pero no quería que pensara que era una mujer fácil, y para ser muy honesta, no se para una puta en una esquina en semana santa si no es porque está bien fea la cosa.

Acostarme con Juan fue una experiencia inolvidable, llegué a pensar que así se sentía ser tomada por un hombre de verdad y seguramente esto era amor. Él se convirtió en mi cliente semanal, siempre tomábamos café en la estación y fue así como me fui involucrando con el movimiento de trabajadores. Eventualmente empecé a escuchar los ideales comunistas que brotaban de esas tierras cansadas y secas; como si fueran estas memorias que atentan escaparse de mis arrugas, dejándome vacía y vieja en esta casita en Tapachula, tan lejos de mi patria y de mi Juan.

Hay etapas que no se olvidan y esos años de revolución no sólo cambiaron mi forma de ver el mundo, sino le dieron sentido a todo lo que se había vivido. Ya no sólo era yo una puta, era una puta revolucionaria. Eventualmente, me aventé a irme en tren al Caribe y buscar el negocio allá. Vivir la vida caribeña. Juan nunca trató de interrumpir con mi oficio, ni se puso en celos ridículos, ¿porque quién pretende hacer de una puta una querida? Nuestra relación me permitió acceso a las salas donde se conversaban estos temas y se incitaba a una huelga regional.

Me había ganado una posición de confianza trabajando de espía para los trabajadores 
y siguiendo a Fallas adonde fuera, para así poder volver al Caribe a contar cómo estaba el pueblo respondiendo a las demandas de los trabajadores caribeños. Esto me permitió viajar por muchas partes del país, y en ningún lugar había suficientes putas, así que era doble la ganancia. Mi sostén era el escondite de los planes secretos y mensajes revolucionarios que se enviaban de plantación a plantación, ¿cuál policía le iba a tocar las tetas a una puta a plena luz del día y negarse a pagarle la tocada? Normalmente, nos paraban en los trenes, con ademanes de intimidarnos, y asegurarnos que si nos veían en las noches nos iban a enseñar de qué estaba hecho el bastón policial. Muchas veces, también fueron nuestros clientes, pero en su gran mayoría tomaban las carnes, las platas y nos dejaban con un poquito menos de dignidad y un par de moretones entre las piernas.

Los bananeros, por su parte, siempre pagaban, y aun cuando a alguno se le pasaba la mano, volvía al día siguiente con el rabo entre las piernas porque sabía que si se metía con una se metía con todas. En esas tierras caribeñas solo a las esposas se les pueden dar palizas sin que nadie se queje, pero las putas, nosotras éramos patrimonio social. Seguramente por eso cuando hablaban del pueblo nosotras nos sentíamos tan identificadas, todo el pueblo vivía en nuestras piernas y nos daban más respeto que a cualquier otra mujer. Así nos fuimos a la huelga, y luchamos hasta más no poder, y también a nosotras nos tocó sostener a los hombres después de la traición, algunos lloraban borrachos en nuestras enaguas y otros se desquitaban con nosotras, siempre pidiendo perdón al día siguiente como perros sarnosos. Y más de una vez, se habló de que la tristeza de la traición nacional era tanta que hasta a más de una puta le daba pena cobrarle a los compañeros. Claro está que después de la Gran Huelga del 31, tuvimos que idear nuevas formas de combatir. Yo me devolví a San José, no soportaba ver un banano más y sentía que en cualquier momento iba a ser yo la que le robaba el bastón al policía para dejarlo hecho añicos.

Ya para el 57, las pocas putas comunistas que quedaron estábamos viejas, y las jovencitas no sabían de las luchas que se habían tomado y la excitación que se vivía en aquellos tiempos. Sin embargo, yo había mantenido a un par de viejos y fieles amigos-clientes, entre ellos Juan Morales, quienes me aseguraban un buen vestido católico y unos guantes de satín para que atendiera eventos del movimiento. Fue así como me encontré en la Sede del Ateneo ese 17 de octubre, escuchando a Víctor Manuel Ríos decir que "el capitalismo está en decadencia y su desaparición es inminente, el futuro le pertenece a los trabajadores, la ciencia y al servicio de la razón, será la base de una sociedad nueva. La pobreza, el vicio y las odiosas diferencias de clase serán sustituidas por la fraternidad proletaria". Anunciaron también que Fallas estaría liderando el movimiento el 19 de octubre en el Parque Morazán, ya que a la una y cincuenta de la madrugada se celebraría el paso del Sputnik por el cielo costarricense.

Camino a casa, las palabras de Ríos daban vueltas en mi cabeza, y no pude evitar pensar en mis queridas Silvia, la Negra Mazamorra y la Lapa Colorida. En aquellos tiempos me decían a mí La Huevo 
Tierno, y no fue hasta ese entonces, después de mi carrera de puta mensajera y comunista, y bien entrada en mi adultez, que me di cuenta de que era por macha, por blanca que a mí me tocaban los muchachos jóvenes y hombres de familias más acomodadas. Todavía recuerdo el día en que entró don Daniel a averiguar en cuánto le dejábamos la acostada a su hijo Julio, que "ya era hora de que se fuera haciendo hombrecito". La Lapa le dijo que sólo si nos hacían descuento en el taller, a lo que él le contestó que ya bastante escándalo se había hecho la vez en pasada que ella había ido a dejar sus zapatillas. Me acuerdo de que la Negra y yo nos volvimos a ver, recordando la tertulia de risas que tuvimos esa tarde cuando La Lapa nos describió las caras de esas mujeres, y especialmente la de esa tal Lola, cuando ella llegó a dejar el pedido. De hecho, la Lola volvió un año más tarde embarazada y con cara de paludismo, todo en esta vida se paga, especialmente la mala fe. Don Daniel me apuntó con su paraguas y preguntó: “¿más o menos cuánto cuesta esta muchachita?" La Lapa, que se había prendido un cigarro, tiró una carcajada al viento y le dijo al hombre que él solo podía costear a la Negra. Fue así como La Negra le pidió al niño Julio que viniera una tarde a apagar el sahumador. Recuerdo ver sus ojos asustados al entrar por la puerta principal; La Negra, sin perder tiempo, se lo llevó arriba y cuando bajó ya era otro.

Esa tarde del 17, todas estas historias de mi juventud se me vinieron a la cabeza, ya no me conocían como La Huevo Tierno. Ya de tierno no tenía nada y ni el color de la piel me aventajaba ahora, la vejez es la ruina de la prostituta, se nos caen las tetas y se nos parte la piel como se nos caen los estándares y se nos parte el monedero. Cada vez ganamos menos por más. Por eso a mí, Juan Morales y su comunismo me salvaron la vida. Me llenaron de un espíritu rebelde y libre. El 18 me preparé para ir, como buena comunista, a escuchar las palabras de Fallas, y antes de irme encendí un par de velas rezándole a Dios por el triunfo de la Unión Soviética y al Diablo para que le jalara las patas a este imperialismo yanqui que nos tenía peor que esta vejez tenía mi negocio, quebradititicos. También le pedí a los ángeles por mi querida Negra, por lo difícil que le tocó por trompuda, y por ese corazón de miel que siempre acudió a los niños del barrio y a nosotras, cuando nos tocaba feo, aunque nunca peor que a ella.

Al llegar al Morazán, había dos mandos de personas y yo me acerqué al lado donde estaba Fallas hablando sobre los éxitos de la Unión Soviética y la importancia de unirnos todos con los trabajadores. A la una y cincuenta de la madrugada pasó volando el Sputnik y era como ver un cometa, o una estrella fugaz en cámara lenta, y mientras unos celebraban y otros rezaban, yo sentí que me picaban los pies, sentí un deseo de ver el mundo, de aprender qué otras injusticias existían más allá de esta tierra de bananos y café.

Al día siguiente, empaqué mis cuatro tiliches en una bolsa de mercado, y pasé por la estación a dejarle una carta a Juan Morales. En esa carta le agradecí por todo y le declaré mi amor infinito $\mathrm{y}$, sin volver a ver atrás, me fui camino al Norte, volando como el Sputnik. 
Debo decir que la vida de prostituta es una vida de aventuras, de aprender a sobrevivir golpes y dolores, a dejar la risa fácil inundar el estómago, a amar a las compañeras, a luchar por vivir, y siempre, siempre, siempre tener algo que ofrecer a cambio. Las puertas del mundo se abren hacia nosotras porque a todo el mundo le gusta acostarse aunque a nadie le gusta aceptarlo. Y así fui subiendo estas tierras centroamericanas, compartiendo parlas con colegas de otros países, y mirando con asombro lo iguales que somos, y cómo todas sus tierras también estaban llenas de bananos y café.

Recuerdo mucho el carisma y la valentía de Rosa, una joven madame en Tegucigalpa. Era más joven que La Lapa, cuando éramos las putillas de La Puebla, más fiera y más glamurosa. Me acuerdo sentarnos a tomar café con aguardiente y mirar el mundo por las ventanas francesas de su linda recámara. Estuve ahí solo una semana, no tenían mucha capacidad de darle hospedaje a una señora como yo, pero nunca olvidaré su gesto de admiración cuando le conté que nosotras, las putas ticas, hacíamos de mensajeras secretas en la lucha. Así me quiero yo recordar, a mis 61 años, valiente, atrevida y comunista.

Ahora vivo en esta vieja casa de Tapachula, me hice un cliente más viejo que yo, pero que tiene buen corazón y me enseñó a leer y a escribir. Vivo mis días tranquila, le aseguro a él su comodidad, y él a cambio me ha abierto las puertas de su casa. No sé si el día de mañana me van a venir a sacar, cuando se le ocurra colgar las tenis, pero sé que aunque no sea Juan Morales, él estaría igual de agradecido que yo, que tengo un techo sobre mi cabeza y comida sobre la mesa. A veces me pregunto qué dirían todos esos mensajes que en mi sostén viajaban y a veces solo por jugar, me gusta escribir mis propios mensajes revolucionarios y metérmelos dentro del sostén cuando voy al mercado. Buena risa nos da cuando me los encuentra este viejo cocodrilo y empieza a cantar que ha llegado a México la guerrillera con más picardía de toda América Latina. 
